\title{
Complications of the Anterior Cervical Discectomy and Fusion
}

\author{
Muthana Ibrahim Jameel ${ }^{1}$, Liwa Abdullah Ali ${ }^{1}$, Ihssan S Nema ${ }^{2 *}$ and \\ Zahraa F Al-Sharshahi ${ }^{3}$ \\ ${ }^{1}$ Department of Neurosurgery, AL-Emamian AlKadhimian Medical City, \\ Baghdad, Iraq \\ ${ }^{2}$ Professor, Department of Surgery, College of Medicine, Al-Nahrain University, \\ Baghdad, Iraq \\ ${ }^{3} B A O$, Department of Neurosurgery, Neurosurgery Teaching Hospital, Baghdad, \\ Iraq \\ *Corresponding Author: Ihssan S Nema, Professor, Department of Surgery, College \\ of Medicine, Al-Nahrain University, Baghdad, Iraq.
}

Received: July 23, 2020

Published: August 19, 2020

(C) All rights are reserved by Ihssan S Nema.,

et al.

\begin{abstract}
Background: Anterior cervical discectomy and fusion (ACDF) means removing the symptomatic disc by an anterior approach with placement of a bone graft or a synthetic cage. Many studies have shown the procedure to be effective, but associated with complications.

Objective: To document and record the type and incidence of complications associated with ACDF, and to find any predisposing factors or associated medical illnesses and other demographic factors or conditions that increase the complications.

Patients and Methods: A prospective review of 48 patients who underwent an anterior cervical discectomy and fusion between (May $\backslash 2012$ - July $\backslash 2014$ ) in two hospitals with an average 6 months follow up.

Results: The sample of patients was classified according to age, gender, diagnosis, complications, associated medical illnesses, level of the operation. Then the complications were analyzed according to these parameters trying to find any predisposing factors or associations. Hoarseness of voice was 79\%, Dysphagia 54\%, Neurapraxia 14.6\%, Other medical illnesses $12 \%$, Infection $4 \%$, Reopening $4 \%$, wrong diagnosis $4 \%$, worsening $4 \%$ and Death $2 \%$.

Conclusion: The complication rate for ACDF is low in experienced hands. Hoarseness is the most common reported complication. Dysphasia, laryngeal edema or a sensation of a lump in the throat are also reported. Associated medical illnesses especially asthmatics and smokers and any patient with chronic cough or respiratory problems are the major cause of complication. Also there is marked association of complications in patients with multisystemic chronic diseases.
\end{abstract}

Keywords: Anterior Cervical Discectomy and Fusion (ACDF); Bone Graft; Fascial Layer

\section{Introduction}

Definition

Anterior Cervical Discectomy with fusion (ACDF) means removing the symptomatic disc from an anterior approach with placement of a bone graft (or prosthetic cage) to encourage bony fusion of the upper and lower vertebral body. Multiple larger studies have shown the procedure to be safe and effective for ventral pathology that is confined to the cervical interspaces such as osteophyte or disc complexes [1].

Surgical anatomy

The key to understanding the anatomy of the anterior approach to the cervical spine lies in appreciating the three fascial layers of the neck. The most superficial fascial layer is the investing layer of deep cervical fascia. The fascia surrounds the neck like a collar, 
but splits around the sternocleidomastoid and trapezius muscles to enclose them. Posteriorly, it joins with the ligamentum nuchae (nuchal ligament). The superficial layer is incised along the anterior border of the sternocleidomastoid muscle. Dividing the layer of fascia allows the sternocleidomastoid to be retracted laterally and separated from the underlying strap muscles. The only structures that lie superficial to it are the platysma muscle (a remnant of the old panniculus carnosus, or muscle of the skin) and the external jugular vein, which can be divided safely if it intrudes into the operative field [2].

The next fascial layer is the pretracheal fascia, which forms a layer between sliding surfaces. It invests the strap muscles and runs from the hyoid bone down into the chest. Its key relationship is with the carotid sheath, which encloses the common carotid artery, the internal jugular vein, and the vagus nerve. The pretracheal fascia is continuous with the carotid sheath at the sheath's lateral margin. Hence, the pretracheal fascia must be divided on the medial border of the carotid sheath so that the carotid sheath can be retracted laterally and the midline structures can be retracted medially. Two sets of vessels, the superior and inferior thyroid vessels, run from the carotid sheath through the pretracheal fascia into the midline. On rare occasions, the thyroid vessels have to be divided to enlarge the exposure [2].

The superior laryngeal nerve, however, which runs with the superior thyroid vessels must be preserved.

The deepest layer of fascia is the prevertebral fascia, a firm, tough membrane that lies in front of the prevertebral muscles. On its surface runs the cervical sympathetic trunk, which lies roughly over the transverse processes of the cervical vertebrae. Beneath the prevertebral fascia are the left and right longus colli muscles.

\section{Landmarks and incision landmarks}

The carotid tubercle is the enlargement of the anterior tubercle of the transverse process of C6. It is larger than all other vertebral tubercles (there is no anterior tubercle of $\mathrm{C} 7$ and may be palpable. The tubercle of C6 is the key surgical landmark in the anterior incision.

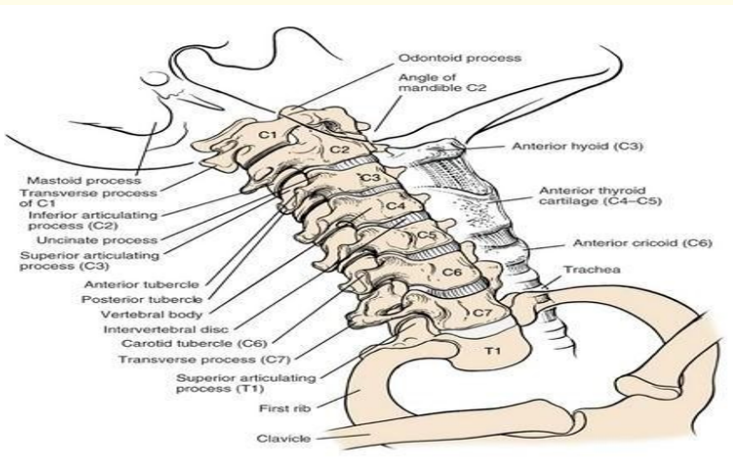

Figure 1
The sternocleidomastoid muscle runs obliquely down the side of the neck from the mastoid process to the sternum and clavicle. It is enclosed in fascia, which must be divided on the medial side before the muscle can be retracted laterally. The nerve supply of the sternocleidomastoid comes from the accessory nerve, which innervates the muscle from its posterior and lateral surfaces. There is no danger of neurologic damage as long as the dissection remains on the medial or anteromedial side of the muscle. If it strays to the posterior side, however, the spinal accessory nerve, which supplies not only the sternocleidomastoid, but also the trapezius, can be damaged [3].

Ideally, the skin incision should run parallel to the cleavage lines of the skin of the neck. Inferiorly and anteriorly, these lines run transversely, making the skin crease incision advantageous. The skin on the anterior part of the neck is thinner and more mobile than is the skin on the back of the neck, because of both the loose subcutaneous tissue and the superficial fascia that remains unconnected to the investing fascia of the neck.

As a result, skin retraction is easy; the skin incision can be moved to accommodate the needs of the surgery. For extensive exposures, a longitudinal, slightly oblique incision can be made parallel to the medial border of the sternocleidomastoid muscle [3]

The platysma muscle is split in line with its fibers. The muscle is difficult to denervate, because most of its nerve supply comes from the cervical branch of the facial nerve and begins in the region of the mandible. In any case, the muscle is not of great functional importance; sewing it carefully during closure can improve the cosmetic appearance of the scar [4].

Dividing the fascia on the anterior border of the sternocleidomastoid muscle reveals the carotid sheath. The sheath contains the common carotid artery, which divides at the upper border of the thyroid cartilage into internal and external carotid arteries. It also contains the internal jugular vein and the vagus nerve. After the plane between the carotid sheath and the trachea and esophagus has been entered, it is easy to develop by blunt dissection [4].

The esophagus however, is a fragile structure that is damaged easily by injudicious retraction. The longus colli muscles lie on the anterior surface of the vertebral column, between $\mathrm{Cl}$ and $\mathrm{T} 3$. The muscles are pointed at their ends and broad in the middle. They must be removed from the vertebral bodies to expose the vertebrae. Removal does not denervate them, because they are innervated segmentally and laterally from their posterior surfaces. Running on the anterolateral surfaces of the longus colli muscles is the cervical sympathetic trunk, with its numerous ganglia. These must be avoided [4].

The two recurrent laryngeal nerves are branches of the vagus nerve. The left recurrent laryngeal nerve descends into the thorax 
within the carotid sheath. It curves around the aortic arch and ascends back in the neck, running between the trachea and esophagus to supply the larynx. The right recurrent laryngeal nerve descends within the carotid sheath and curves around the subclavian artery before ascending into the neck at a higher level than the left recurrent laryngeal nerve. In addition, the right recurrent laryngeal nerve is, on rare occasions, aberrant, leaving the carotid sheath at a higher level and crossing the operative field at the level of the thyroid gland. Thus, left-sided approaches often are preferred. The nerves usually are safe as long as retractors are placed correctly underneath the longus colli muscles [4].

\section{Complications}

Although complications are fairly rare, as with any surgery, the following risks may be associated with ACDF:

- Infection

- Excessive bleeding, which may require blood transfusion

- Anesthesia Complications, An adverse reaction to anesthesia

- $\quad$ Chronic neck or arm pain

- Inadequate symptom relief

- $\quad$ Damage to the nerves and nerve roots

- Damage to the spinal cord (about 1 in 10,000 ), resulting in paralysis

- $\quad$ Spinal instability

- $\quad$ Damage to the esophagus, trachea, or vocal cords

- Injury to the carotid or vertebral arteries, which could result in stroke

- Fusion that does not heal

- Instrumentation breakage, failure, hardware fracture, implant migration

- Persistent swallowing or speech disturbance

- Leakage of cerebral spinal fluid

- Transitional Syndrome, adjacent segment disease

- $\quad$ Death (mortality).

The benefits of surgery should always be weighed carefully against its risks. Although a large percentage of cervical spine pa- tients report significant pain relief after surgery, there is no guarantee that surgery will help every individual.

Intra-operative complications:

- Problems associated with particular approaches to the spine used at the time of surgery.

- Issues related to patient positioning on the operating table.

- Neurological deterioration.

Postoperative complications fall into four broad categories:

- General medical complications.

- $\quad$ Problems related to specific surgical approaches.

- Postoperative infection.

- Loss of internal fixation

\section{Aim of the Study}

The objective of the study is:

- To document and record the type and incidence of complication associated with ACDF

- $\quad$ To find any predisposing factors or associated medical illnesses and other demographic factors or conditions, that increase the complications.

\section{Patients and Methods}

A prospective review of 48 patients who underwent an anterior cervical discectomy and fusion between (May $\backslash 2012$-July $\backslash 2014$ ) in Al-Emamain Alkadhimain Medical City, Neurosurgical ward, and in Neurosurgery Teaching Hospital, Baghdad, Iraq, with an average 6 months follow up was conducted [11]. patients had multilevel degenerative disease, 4 of them with additional kyphosis (swan neck).

All patients underwent anterior cervical discectomy. Two had 2 level discectomy with simultaneous instrumentation and fusion. 29 were females and 19 were males.

Age distribution between 27 - 58 years (the average is 42.5 ).

Weight of the patients ranges from 55 to $115 \mathrm{~kg}$. and their body built (body mass index) was taken into consideration.

Every associated preoperative medical illnesses and conditions were thoroughly investigated and recorded. All early complications 
were reviewed and recorded as major or minor depending on the severity and need for further intervention.

All patients remained in a rigid cervical orthosis for one month post-operatively. Fusion was assessed by plain radiography. For an $\mathrm{x}$-ray to be fused there had to be no radiolucency at the endplates and less than $2 \mathrm{~mm}$ of motion on flexion-extension films. 32 of the 48 patients were referred to physiotherapy after the removal of stitches (one week from the operation).

Diagnoses were 12 cervical spondylotic myelopathy (CSM), 8 ossification of posterior longitudinal ligament (OPLL), 22 cervical disc herniation (CDH), 6 cervical spondylotic myelopathy and radiclopathy (CSAR).

Average operative duration was 3.5 hours.

A preoperative MRI was used to confirm the amount of nerve root or spinal cord compression.

All operations were conducted from the left side (to avoid injury to the re- current laryngeal nerve) and no right sided incision was practiced to compare.

X-rays were measured at each interval to determine any changes in the range of motion. Other parameters that were assessed include smoking, employment status (return to work), and preoperative pain or neurological function.

Other complications, like post-operative myocardial infarction with recovery period of 3 months constitute a major burden to the patient and her family. Anterior graft migration not requiring revision, and it was completely asymptomatic finding during the routine X-ray post-operative checking. Dural tear discovered during the operation without any post-operative sequels. No neurological injury reported.

Major complications included recurrent laryngeal nerve palsy does not happen. Esophageal perforation requiring temporary percutaneous gastrostomy and a major exploration surgery by vascular surgeon ended eventually in death of the patient. There is one case with failure of instrumentation requiring revision, he was an obese and diabetic man.

We used Mc Cormick and Aminoff-Logue Scale to evaluate the patients for any complications that happened post-operatively.

\begin{tabular}{|l|c|}
\hline Grade & Definition \\
\hline I & $\begin{array}{r}\text { Neurologically normal, normal gait, mild focal } \\
\text { deficit, not affecting function }\end{array}$ \\
\hline II & $\begin{array}{r}\text { Sensorimotor deficit affecting function, gait dif- } \\
\text { ficulty, severe pain, impairing QOL }\end{array}$ \\
\hline III & $\begin{array}{c}\text { Severe neurological deficit, require cane or brace } \\
\text { for ambulation, not function independently }\end{array}$ \\
\hline IV & $\begin{array}{c}\text { Severe deficit, require wheelchair with bilateral } \\
\text { upper extremity impairment, totally independent } \\
\text { functionally }\end{array}$ \\
\hline
\end{tabular}

Table 1: Mc Cormick scale.

\begin{tabular}{|c|c|}
\hline Grade & Definition \\
\hline Gait & Onset of leg weakness \\
\hline 1 & Restricted exercise tolerance \\
\hline 2 & Requires stick or support for walking \\
\hline 3 & Require crutches \\
\hline 4 & Confined to bed or wheelchair \\
\hline 5 & Hesitancy, urgency, or frequency \\
\hline Matuition & Total incontinence \\
\hline Mild & \\
\hline Moderate & Urine retention or occasional incontinence \\
\hline Severe & Constipation \\
\hline Bowel & Occasional incontinence \\
\hline Mild & Fecal incontinence \\
\hline Moderate & \\
\hline Severe & \\
\hline
\end{tabular}

Table 2: Aminoff-Logue scale.

\section{Results}

Patients were classified according to gender. 29 of the 48 were males that is $60 \%$, and 19 were females, that is $40 \%$.

\begin{tabular}{|l|c|c|c|c|c|c|c|}
\hline & Hoarseness & Dysphagia & Neurapraxia & Infection & Reopening & $\begin{array}{c}\text { Wrong } \\
\text { level }\end{array}$ & $\begin{array}{c}\text { Wrong } \\
\text { diagnosis }\end{array}$ \\
\hline Males & 20 & 12 & 4 & 1 & 1 & 1 & 1 \\
\hline & $69.00 \%$ & $41.37 \%$ & $13.79 \%$ & $3.44 \%$ & $3.44 \%$ & $3.44 \%$ & $3.44 \%$ \\
\hline Females & 18 & 14 & 3 & 1 & 1 & 1 & 1 \\
\hline & $94.73 \%$ & $73.68 \%$ & $15.78 \%$ & $5.26 \%$ & $5.26 \%$ & $5.26 \%$ & $5.26 \%$ \\
\hline
\end{tabular}

Table 3: Gender versus complications. 


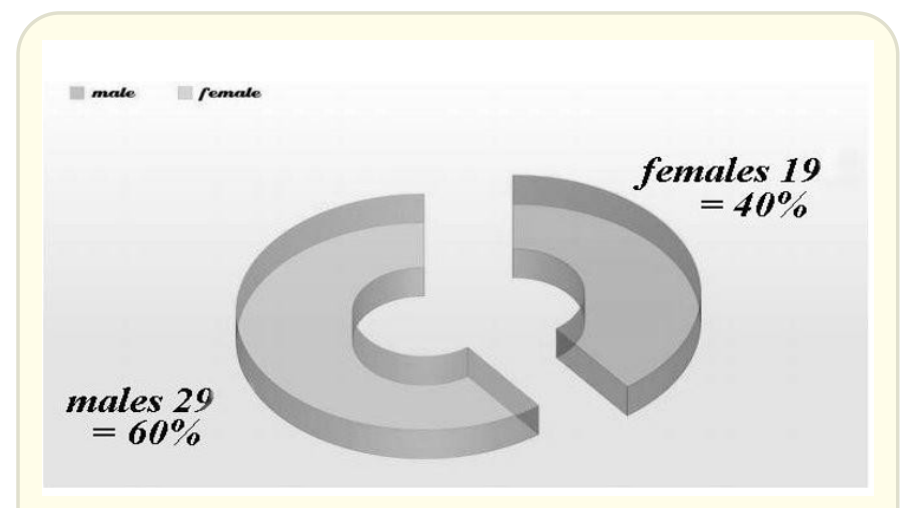

Figure 2: Gender incidence.
Patients were also classified according to their age into 4 groups. The most common age was between 40 - 50 years old.

\begin{tabular}{|l|c|}
\hline \multicolumn{1}{|c|}{ Age } & Number and percentage \\
\hline$<20$ years & None \\
\hline $20-30$ & 2 patients $=4 \%$ \\
\hline $30-40$ & 16 patients $=33 \%$ \\
\hline $40-50$ & 25 patients $=52 \%$ \\
\hline $50-60$ & 5 patients $=10 \%$ \\
\hline$>60$ years & None \\
\hline
\end{tabular}

Table 4: Age incidence.

\begin{tabular}{|l|c|c|c|c|c|c|c|}
\hline & Hoarseness & Dysphagia & Neurapraxia & Infection & reopening & $\begin{array}{c}\text { Wrong } \\
\text { level }\end{array}$ & Wrong diagnosis \\
\hline $20-30$ & 1 & 1 & & & & & \\
\hline & $50.00 \%$ & $50.00 \%$ & & & & & \\
\hline $30-40$ & 10 & 6 & 3 & & 1 & & $6.25 \%$ \\
\hline & $62.50 \%$ & $37.50 \%$ & $17.75 \%$ & & $6.25 \%$ & & 1 \\
\hline $40-50$ & 24 & 17 & 4 & 2 & 1 & 2 & $4.00 \%$ \\
\hline & $96.00 \%$ & $68.00 \%$ & $16.00 \%$ & $8.00 \%$ & $4.00 \%$ & $8.00 \%$ & \\
\hline $50-60$ & 3 & 2 & & & & & \\
\hline & $60.00 \%$ & $40.00 \%$ & & & & & \\
\hline
\end{tabular}

Table 5: Age versus complications.

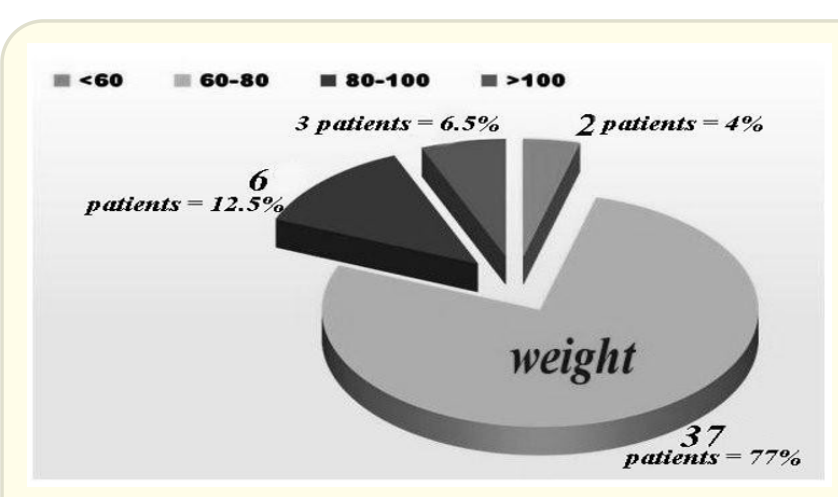

Figure 3: Classification according to weight.
Patients were classified according to their weight into 4 groups.

Those below $60 \mathrm{Kg}$ were only 2 patients (4\%). 60 - $80 \mathrm{Kg}$ were the majority of cases (77\%). 80 - $100 \mathrm{Kg}$ were patients (12.5\%).

Only 3 patients were above $100 \mathrm{Kg}(6.5 \%)$.

According to the WHO classification of Body Mass Index, our patients were classified into only 2 groups: Normal; 21 patients (43.75\%) and over-weight 27 patients (56.25\%).

We did not have any under-weight, nor morbid obese patients.

\begin{tabular}{|l|c|c|c|c|c|c|c|}
\hline & Hoarseness & Dysphagia & Neurapraxia & Infection & Reopening & $\begin{array}{c}\text { Wrong } \\
\text { level }\end{array}$ & Wrong diagnosis \\
\hline Normal & 11 & 1 & & & & & \\
\hline & $52.38 \%$ & $4.76 \%$ & & & & & \\
\hline Over-weight & 27 & 25 & 7 & 2 & 2 & 2 & 2 \\
\hline & $100.00 \%$ & $92.59 \%$ & $25.92 \%$ & $7.40 \%$ & $7.40 \%$ & $7.40 \%$ & $7.40 \%$ \\
\hline
\end{tabular}

Table 6: Weight versus complications. 


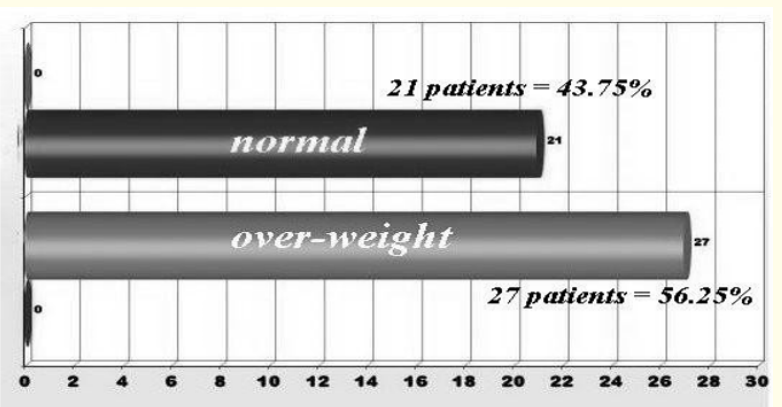

Figure 4: Classification of patients according to body mass index.

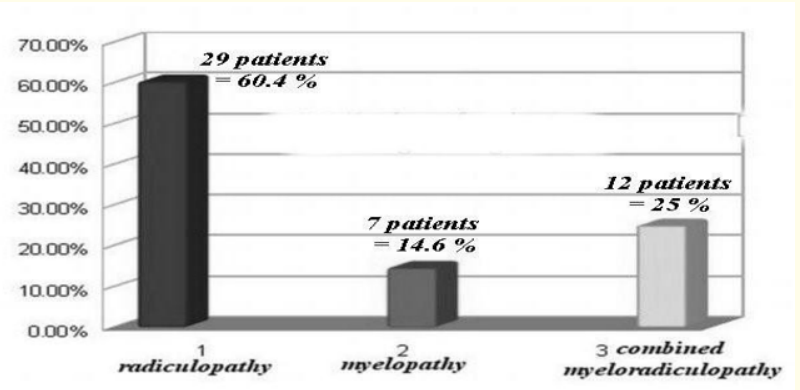

Figure 5: Distribution of patients according to the diagnosis.

$60.4 \%$ (29) of the patients presented with the clinical picture of radiculopathy, $14.6 \%$ (7) with pure myelopathy, and 25\% (12) had a combined myeloradiculopathy.

\begin{tabular}{|l|c|c|c|c|c|c|c|}
\hline & Hoarseness & Dysphagia & Neurapraxia & Infection & Reopening & $\begin{array}{c}\text { Wrong } \\
\text { level }\end{array}$ & $\begin{array}{c}\text { Wrong } \\
\text { diagnosis }\end{array}$ \\
\hline Radiculopathy & 22 & 17 & 3 & & 1 & 1 & $3.44 \%$ \\
\hline & $75.86 \%$ & $58.62 \%$ & $10.34 \%$ & & $3.44 \%$ & 1 & 1 \\
\hline Myelopathy & 6 & 1 & 2 & 2 & & $14.28 \%$ & $14.28 \%$ \\
\hline & $85.71 \%$ & $14.28 \%$ & $28.57 \%$ & $28.57 \%$ & & 1 & 1 \\
\hline & 10 & 5 & 2 & & $8.33 \%$ & & $8.33 \%$ \\
\hline
\end{tabular}

Table 7: Diagnosis versus complications.

\begin{tabular}{|c|c|c|c|c|c|c|c|}
\hline & $\begin{array}{c}\text { Hoarse- } \\
\text { ness }\end{array}$ & Dysphagia & Neurapraxia & Infection & Reopening & $\begin{array}{c}\text { Wrong } \\
\text { level }\end{array}$ & Wrong diagnosis \\
\hline \multirow[t]{2}{*}{ C5-6 } & 21 & 12 & 2 & 1 & 1 & 1 & 1 \\
\hline & $87.50 \%$ & $50.00 \%$ & $8.33 \%$ & $4.16 \%$ & $4.16 \%$ & $4.16 \%$ & $4.16 \%$ \\
\hline \multirow[t]{2}{*}{ C4-5 } & 8 & 6 & 2 & & 1 & 1 & \\
\hline & $66.66 \%$ & $50.00 \%$ & $16.66 \%$ & & $8.33 \%$ & $8.33 \%$ & \\
\hline \multirow[t]{2}{*}{ C6-7 } & 3 & 2 & & 1 & & & \\
\hline & $60.00 \%$ & $40.00 \%$ & & $20.00 \%$ & & & \\
\hline \multirow[t]{2}{*}{ C3-4 } & 1 & 1 & & & & & \\
\hline & $50.00 \%$ & $50.00 \%$ & & & & & \\
\hline \multirow[t]{2}{*}{ 2Level } & 3 & 3 & 1 & & & & \\
\hline & $100.00 \%$ & $100.00 \%$ & $33.33 \%$ & & & & \\
\hline \multirow[t]{2}{*}{ Corpectomy } & 2 & 2 & 2 & & & & \\
\hline & $100.00 \%$ & $100.00 \%$ & $100.00 \%$ & & & & \\
\hline
\end{tabular}

Table 8: Level of the operation versus complications. 


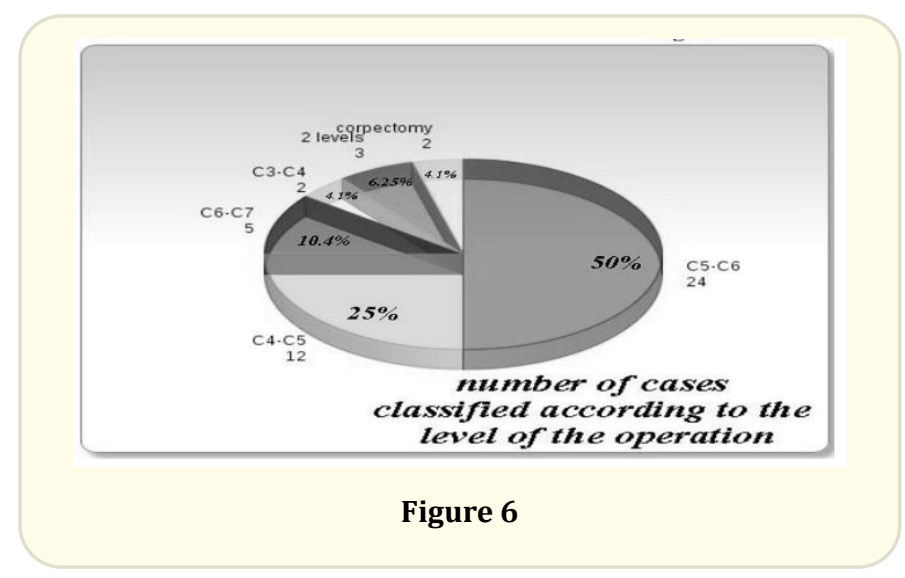

$79 \%$ (38) of the patients suffered from mild hoarseness.

$54 \%$ (26) of the patients complained from postoperatively of varying degrees of dysphagia.

$14.6 \%$ (7) of the patients have some sort of neck and $\backslash$ or shoulder and $\backslash$ or upper arm pain and numbness caused mostly by neurapraxia.

Other complications (12\%), usually those caused by the associated medical illnesses (raised blood pressure, hyper- or hypoglycaemia, arrhythmias, ischemic chest pain, dyspnoea, allergies to drugs or to blood, epileptic fits, gastritis and peptic ulceration).

Although patients were carefully selected for the surgery, a significant number of them were previously (preoperatively) diagnosed with one or more medical comorbidity.

$22.91 \%$ were diagnosed with multiple medical illnesses $16.66 \%$ with hypertension $10.41 \%$ with diabetes $14.58 \%$ with other rare

\begin{tabular}{|l|c|c|}
\hline \multicolumn{1}{|c|}{ Medical illness } & Number & Percent \\
\hline Multisystemic & 11 & $22.91 \%$ \\
\hline Hypertension & 8 & $16.66 \%$ \\
\hline Respiratory & 7 & $14.58 \%$ \\
\hline Smoking & 5 & $10.41 \%$ \\
\hline Diabetes & 5 & $10.41 \%$ \\
\hline Allergies & 4 & $8.33 \%$ \\
\hline Rheumatoid & 3 & $6.25 \%$ \\
\hline $\begin{array}{l}\text { Motor/sensory } \\
\text { deficit }\end{array}$ & 2 & $4.16 \%$ \\
\hline Epilepsy & 2 & $4.16 \%$ \\
\hline Cardio-pulmonary & 2 & $4.16 \%$ \\
\hline $\begin{array}{l}\text { Other rare ill- } \\
\text { nesses }\end{array}$ & 7 & $14.58 \%$ \\
\hline
\end{tabular}

Table 9: Incidence of pre-operative associated medical illnesses.

illnesses like hepatic or renal failure, gout, thyroid disease, hormonal imbalance, peptic ulcers, and hemophilia.

These complications causes major impact on the success of the operation if no enough attention is paid to avoid them or to anticipate their effects. The most serious one is smoking (48\%), multisystemic illnesses (43\%) and respiratory problems like chronic cough and asthma (42.6\%).

This table reflects the effect of having a medical illness on the incidence of complications.

\begin{tabular}{|l|c|c|c|c|c|c|}
\hline & No & Hoarseness & Dysphagia & Neurapraxia & Infection & Reopening \\
\hline Multisystemic & 11 & $10(90 \%)$ & $7(63 \%)$ & $5(45 \%)$ & $1(9 \%)$ & $1(9 \%)$ \\
\hline Hypertension & 8 & $5(62 \%)$ & $2(25 \%)$ & $2(25 \%)$ & - & - \\
\hline Respiratory & 5 & $2(40 \%)$ & $2(40 \%)$ & $1(20 \%)$ & $1(20 \%)$ & - \\
\hline Smoking & 4 & $3(75 \%)$ & $2(50 \%)$ & $1(25 \%)$ & - & - \\
\hline Diabetes & 3 & $1(33 \%)$ & $1(33 \%)$ & $1(33 \%)$ & - & - \\
\hline Allergies & 2 & - & - & - & - & - \\
\hline Rheumatoid & 2 & - & - & - & - & - \\
\hline $\begin{array}{l}\text { Motor/sensory } \\
\text { deficit }\end{array}$ & 2 & - & - & - & - & - \\
\hline Epilepsy & 7 & $5(71 \%)$ & $4(57 \%)$ & $3(43 \%)$ & $1(14 \%)$ & $2(28 \%)$ \\
\hline Cardio-pulmonary & 5 & $5(100 \%)$ & $4(80 \%)$ & $2(40 \%)$ & $1(20 \%)$ & - \\
\hline Other rare illnesses & 7 & $1(14 \%)$ & $1(14 \%)$ & $1(14 \%)$ & - & $1(14 \%)$ \\
\hline
\end{tabular}

Table 10: Medical illnesses versus complications. 


\begin{tabular}{|l|c|c|c|c|c|c|c|c|c|c|}
\hline & Hoarseness & Dysphagia & $\begin{array}{c}\text { Neura- } \\
\text { praxia }\end{array}$ & others & Infection & $\begin{array}{c}\text { Re } \\
\text { opening }\end{array}$ & $\begin{array}{c}\text { Wrong } \\
\text { Level }\end{array}$ & $\begin{array}{c}\text { Wrong } \\
\text { Diagnosis }\end{array}$ & $\begin{array}{c}\text { Worsen- } \\
\text { ing of the } \\
\text { signs and } \\
\text { symptoms }\end{array}$ & $\begin{array}{c}\text { Death } \\
\text { Early }<3 \\
\text { weeks }\end{array}$ \\
\cline { 2 - 11 } & 38 & 26 & 7 & 6 & 2 & & & & 1 \\
\hline $\begin{array}{l}\text { Late 3 } \\
\text { weeks-6 } \\
\text { months }\end{array}$ & $79.00 \%$ & $54.00 \%$ & $14.60 \%$ & $12.50 \%$ & $4.00 \%$ & & & & $2.00 \%$ \\
\hline
\end{tabular}

Table 11: Complications were classified to early (less than 3 weeks) and late (from 3 weeks to 6 months).

All our patients suffer some sort of complication during the 6 months period of follow up, and they were classified into two groups of early complications within the first 3 weeks of the operation, and late complications after 3 weeks and till 6 months.

\section{Discussion}

Age

Feiz-Erfan., et al. and Flynn., et al. found no significant association with age, while Boakye and colleagues found highly associated complication rates in old age (above 65 years) $[5,6]$.

In our study, the oldest patient was 58 years old, and we did not find any Significant association.

Gender

Feiz-Erfan., et al. and Flynn., et al. found high rates of complications among males, and they attributed this to the high rates of smoking comparing to females.

While Boakye and colleagues did not find any significant association $[5,6]$.

In our study we also did not found any significant association.

Weight

Feiz-Erfan., et al. and Flynn., et al. did not find any significant association between the complication rates of ACDF operations and obesity. While Boakye and colleagues found significant association, and the most significant one was reopening and adjacent segment disease $[5,6]$.

In our study we have no obese patients (according to WHO classification of weight, we had only over-weight patients). Still we found significant association between over-weight and the rates of complications (all kinds of complications)
The presenting pathology

Boakye and colleagues found more complication rates in patients with cervical spondylotic myelopathy than in patients with radiculopathy (particularly neurapraxia soon after the operation). While Feiz-Erfan., et al. and Flynn., et al. did not find any significant association regarding the presenting pathology $[5,6]$.

In our study we also did not found any significant association

\section{Level of the operation}

Boakye and colleagues did not find any significant association between the level of the operation and the rate of complication Feiz-Erfan., et al. and Flynn., et al. also did not find any significant association, but they mention the strong as- sociation between multi-level plating and the increased rates of complications $[5,6]$. In our study we also did not found any significant association regarding the level. But we found strong association when there is multi-level operations and when there is corpectomy.

\section{The associated medical illnesses}

Boakye and colleagues found more complication rates in patients with multiple medical illnesses than in patients with no illness or with only one illness. The most significant association was between diabetes plus rheumatoid arthritis and infection $[5,6]$

While Feiz-Erfan., et al. and Flynn., et al. find significant association even with only one medical illness. The most significant one was smoking. Also they did not find any significant differences between the nature or the sort of illness and a particular kind of complication [5,6-28].

In our study we find significant association between smoking, multiple medical Illnesses and respiratory problems (Asthma and chronic cough) to be associated with high rate of hoarseness of voice and dysphagia. 
To compare our result with each other and with other similar studies we need a fair non biased scale.

Examples of these scales are shown here in the table 12, namely JOA outcome score, Nurick scale, Mc Cormick-Aminoff scale and Oswestry score.
As any one could see, there are a great differences in results between studies with different numbers of patients and different periods of follow up.

\begin{tabular}{|c|c|c|c|c|}
\hline Worsening & $\begin{array}{l}\text { Remained } \\
\text { the same }\end{array}$ & Improvement & Scale & Author \\
\hline $11 \%$ & $7 \%$ & $82 \%$ & $\begin{array}{l}\text { Japanese } \\
\text { Orthopaedic } \\
\text { Association } \\
\text { Outcome scale }\end{array}$ & $\begin{array}{l}\text { Miyazaki and kirita } 155 \text { patients who under- } \\
\text { went multilevel iaminectomy at a mean follow } \\
\text { up of } 6 \text { months (2012) }\end{array}$ \\
\hline $8 \%$ & $55 \%$ & $37 \%$ & Nurick scale & $\begin{array}{l}\text { Ebersold., et al. } 51 \text { Patients underwent Laminec- } \\
\text { tomy long-Term followup ( } 9 \text { years . 2001-2010) }\end{array}$ \\
\hline $11 \%$ & $29 \%$ & $60 \%$ & $\begin{array}{l}\text { Mc cormick- } \\
\text { Aminoff scale }\end{array}$ & $\begin{array}{l}\text { Kihara., et al. } 151 \text { Patients with CSM Who un- } \\
\text { derwent Laminopalsty At } 1 \text { year follow up }\end{array}$ \\
\hline $40 \%$ & $17 \%$ & $43 \%$ & Oswestry score & $\begin{array}{c}\text { Seichi., et al. reviewed } 60 \text { patients ( } 35 \text { with } \\
\text { OPLL and } 25 \text { with CSM) who underwent } \\
\text { French-window Laminoplasty mean Follow up } \\
\text { of } 5 \text { years }\end{array}$ \\
\hline
\end{tabular}

\section{Table 12}

Among many studies, we found that Mc Cormick-Aminoff scale is the most practical and fair, even when comparing studies with huge differences like the one shown here.

Feiz-Erfan and Flynn., et al. study of 92 patients with mean follow up period of 12 months, was compared with Boakye and col- leagues 46,562 patients with 5 - 15 years follow up period. And as shown here the results were more or less similar provided that we use Mc Cormick-Aminoff scale for comparison.

Comparing our results using the same scale with both of them would be a fair and reasonable comparison.

\begin{tabular}{|l|c|c|c|c|c|}
\hline Worsening & The same & $\begin{array}{c}\text { Good } \\
\text { results }\end{array}$ & $\begin{array}{c}\text { Follow up } \\
\text { Period }\end{array}$ & Scale & Author \\
\hline $11.9 \%$ & $25 \%$ & $63.1 \%$ & 12 & Mc cormick- & $\begin{array}{c}\text { Feiz-Erfan I, Klopfenstein JD, Bambakidis } \\
\text { NC., } \text { et al. and Flynn., } \text { et al. } 92 \text { patients for } \\
\text { Anterior approach Discectonmy and fusion }\end{array}$ \\
\hline $17.3 \%$ & $23.4 \%$ & $59.3 \%$ & $5-15$ & Mc cormick- & $\begin{array}{c}\text { Boakye and colleagues Schmidek and Sweet } \\
\text { Operative Neurosurgical Techniques 6th edi- } \\
\text { tion 46,562 patients pool }\end{array}$ \\
\hline $\begin{array}{l}10.4 \%=5 \\
\text { patients }\end{array}$ & $\begin{array}{c}16.6 \%=8 \\
\text { patients }\end{array}$ & $\begin{array}{c}73 \%=35 \\
\text { patients }\end{array}$ & $\begin{array}{c}\text { Years } \\
\text { months }\end{array}$ & $\begin{array}{c}\text { Aminoff scale } \\
\text { Aminoff scale }\end{array}$ & $\begin{array}{c}\text { Our study 48 patients who underwent an } \\
\text { anterior cervical discectomy and fusion } \\
\text { between (May } \backslash 2012 .- \text { July } \backslash 2013) \text { in 2 hos- } \\
\text { pitals Neuroscience Hospital and Nursery } \\
\text { Home Hospital }\end{array}$ \\
\hline
\end{tabular}

Table 13 


\section{Conclusion}

- The commonest complications were hoarseness of voice $79 \%$ and dysphagia $54 \%$, and the second most common complications were neurapraxia $14.6 \%$ and other complications related to the previous medical illnesses (not directly related to the operation) $12 \%$.

- The factors that were more than other factors to be related to our complications is asthma, smoking, and chronic cough (all are respiratory), then comes multiple medical comorbidity.

- Hoarseness is the most common reported complication and is usually the result of retractor pressure on the larynx.

- Dysphasia, laryngeal edema, or a sensation of a lump in the throat owing to swelling of the pharyngeal constrictor muscle can also be attributed to retractor blade placement. Careful selection of blade size and meticulous placement should reduce these self-resolving complaints.

\section{Recommendations}

- Intraoperative spinal cord monitoring such as motor evoked potentials (MEPs), either alone or in combination with somatosensory evoked potentials (SSEPS), has been used extensively as a means of reducing intraoperative spinal cord injury.

- The O-arm Surgical Imaging System is a multi-dimensional surgical imaging platform that is optimized for use in spine and trauma-related surgeries. It provides real-time, intra-operative imaging of a patient's anatomy with high quality images and a large field-of-view in both two and three dimensions. O-Arm Scanner is a new 3D X-ray machine used during operations. These live pictures make surgery easier, quicker and safer.

\section{Bibliography}

1. Murphy MG and Gado M. "Anterior cervical discectomy without interbody bone graft". Journal of Neurosurgery 37.1 (2009): 71-74.

2. Hoang Le., et al. "Historical review of cervical arthroplasty". Neurosurgery Focus 17.3 (2004): E1.

3. Omeis I., et al. "History of instrumentation for stabilization of the subaxial cervical spine". Neurosurgery Focus 19.1 (2004) E10.
4. Toru Yamagata., et al. "Outcomes of contemporary use of rectangular titanium stand-alone cages in anterior cervical discectomy and fusion: Cage subsidence and cervical alignment". Journal of clinical Neuroscience 19.12 (2012): 1673-1678.

5. Jho HD and Kim WK. "Anterior microforaminotomy for treatment of cervical radiculopathy: part1, disc-preserving "functional cervical disc surgery". Neurosurgery 51 (2012): S46-S53.

6. Hakuba A. "Trans-unco-discal approach: A combined anterior and lateral approach to cervical discs". Journal of Neurosurgery 45 (2006): 284-291.

7. Martin AN. "Anterior cervical discectomy with and without interbody bone graft". Journal of Neurosurgery 44.3 (2011): 290-295.

8. Hankinson HL and Wilson CB. "Use of the operating microscope in anterior cervical discectomy without fusion". Journal of Neurosurgery 43.4 (2012): 252-256.

9. Hardy RW. Complication of anterior cervical surgery, in Tarlov ED (ed): Complications of Spinal Surgery. Park Ridge, American Association of Neurological Surgeons (2012): 85-95.

10. WS Nohnen LM., et al. "Artificial disc replacement with the modular type SB Charite 111: 2 year results in 50 prospectively studies patients". European spine Journal 8 (2005): 210-217.

11. Wigfield JL., et al. "The new Frenchay artificial cervical joint: results from a 2 year pilot study". Spine 27 (2002): 2446-2452.

12. Simon Bayerl., et al. "Single and multi level anterior decompression and fusion for cervical spondylotic myelopathy. A long term follow-up with a minimum of 5 years". Clinical Neurology and Neurosurgery 115 (2013): 1966-1971.

13. Dowd GC and Wirlh FP. "Anterior cervical discectomy: is fusion necessary?". Journal of Neurosurgery 90 (2006): 8-12.

14. Suat E., et al. "A comparison of changes over time and pathophysiology in cervical foraminal height after tri- cortical iliac graft or polyetheretherketone cage placement following anterior discectomy". Journal of Neurosurgery (2007).

15. Shiuh-Lin Hwang., et al. "Outcome Analyses of Inter body Titanium Cage Fusion Used In the Anterior Discectomy for Cervical Degenerative Disc Disease". Journal of Spinal Disorders and Techniques 18.4 (2005): 326-331.

16. Cherubino P., et al. "Degenerative arthritis of the adjacent spinal joint following anterior cervical spinal fusion: clinicoradiologic and statistical correlations". Italian Journal of Orthopaedics and Traumatology 16 (2002): 533-543.

17. Hilibrand A S., et al. "Radiculopathy and myelopathy at segments adjacent to the site of a previous anterior cervical arthrodesis". Journal of Bone and Joint Surgery 81 (2002): 519528. 
18. Steel TR., et al. "Intraoperative wound infiltration With bupivacaine in patients undergoing spine surgery". Journal of Clinic Neuroscience 5.3 (2008): 298-303.

19. Hunter L Y., et al. "Radiographic changes following anterior cervical fusion and Late radiographic findings after anterior cervical fusion for spondylotic myeloradiculopathy". Spine 5 (2000): 399-401.

20. Palma L., et al. "Favourable long-term clinical outcome after anterior cervical discectomy. A study on a series of 125 patients undergoing surgery a mean of 11 years earlier". Acta Neurochirurgica (Wien) 152.7 (2010): 1145-1152.

21. Martin BI., et al. "Reoperation rates following cervical spine surgery and the influence of spinal fusion procedures". Spine 32 (2007): 382-387.

22. H Richard Winn., et al. Neurological Surgery 6th Edition, Pathophysiology, natural history and clinical features of neck paln, cervical radiculopathy and myelopathy. Journal of Bone and Joint Surgery 10 (2002): 1872-1881.

23. H Richard Winn., et al. "Youmans Neurological Surgery 6th edition, Modified anterior approach to the cervico-thoracic junction". Spine 16 (1991): S542-S547.

24. H Richard Winn., et al. Youmans Neurological Surgery 6th edition Current treatment of osteosarcoma Cancer Investigation 9 (2001): 292.

25. H Richard Winn., et al. "Youmans Neurological Surgery 6th edition Chordoma of the mobil spine: Fifty years of experience". Spine 31 (2006): 493.

26. Morio Y., et al. "Correlation between operative outcomes of cervical compression myelopathy and MRI of the spinal cord". Spine 26 (2001): 1238-1245.

27. Feiz-Erfan I., et al. "Surgical management of cervical disc disease: from no fusion to fusion and back again". Clinical Neurosurgery 52 (2005): 331-337.

28. Ishihara H., et al. "Adjacent segment disease After anterior cervical lnterbody fusion". Spine Journal 4 (2004): 624-628.

\section{Assets from publication with us}

- Prompt Acknowledgement after receiving the article

- Thorough Double blinded peer review

- Rapid Publication

- Issue of Publication Certificate

- High visibility of your Published work

Website: www.actascientific.com/

Submit Article: www.actascientific.com/submission.php

Email us: editor@actascientific.com

Contact us: +919182824667 